\title{
Henry Horst Mantsch - A visionary biomedical spectroscopist and a true interdisciplinary professional
}

\section{Parvez I. Haris}

Faculty of Health and Life Sciences, De Montfort University, Leicester, LE1 9BH, United Kingdom E-mail:pharis@dmu.ac.uk

Henry Mantsch (see Fig. 1) was born in Romania in 1935. He studied chemistry at the Cluj-Napoca University from 1953 till 1958. Subsequently, he obtained his PhD degree in Physical Chemistry in 1964 from the Institute of Chemistry of the Romanian Academy of Sciences. His PhD thesis focused on infrared spectroscopy. Henry moved to the Technical University in Munich as Humboldt Research Fellow for two years (1966-1967). There he secured a German Dr. rer. nat. habil. (DSc). Henry migrated to Canada in 1968 to work with Norman Jones at the National Research Council (NRC) in Ottawa. The

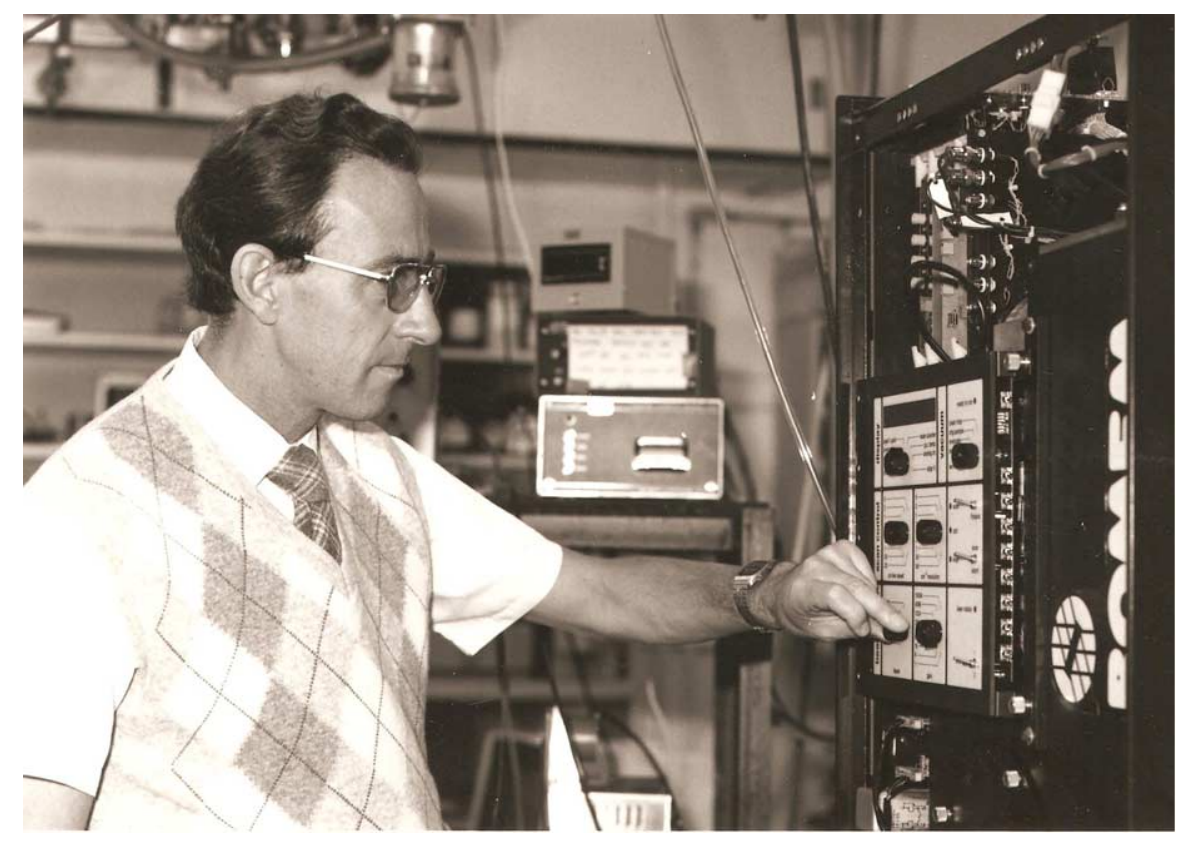

Fig. 1. Photograph of Henry Mantsch next to a FTIR spectrometer (photograph kindly provided by Henry Mantsch). 


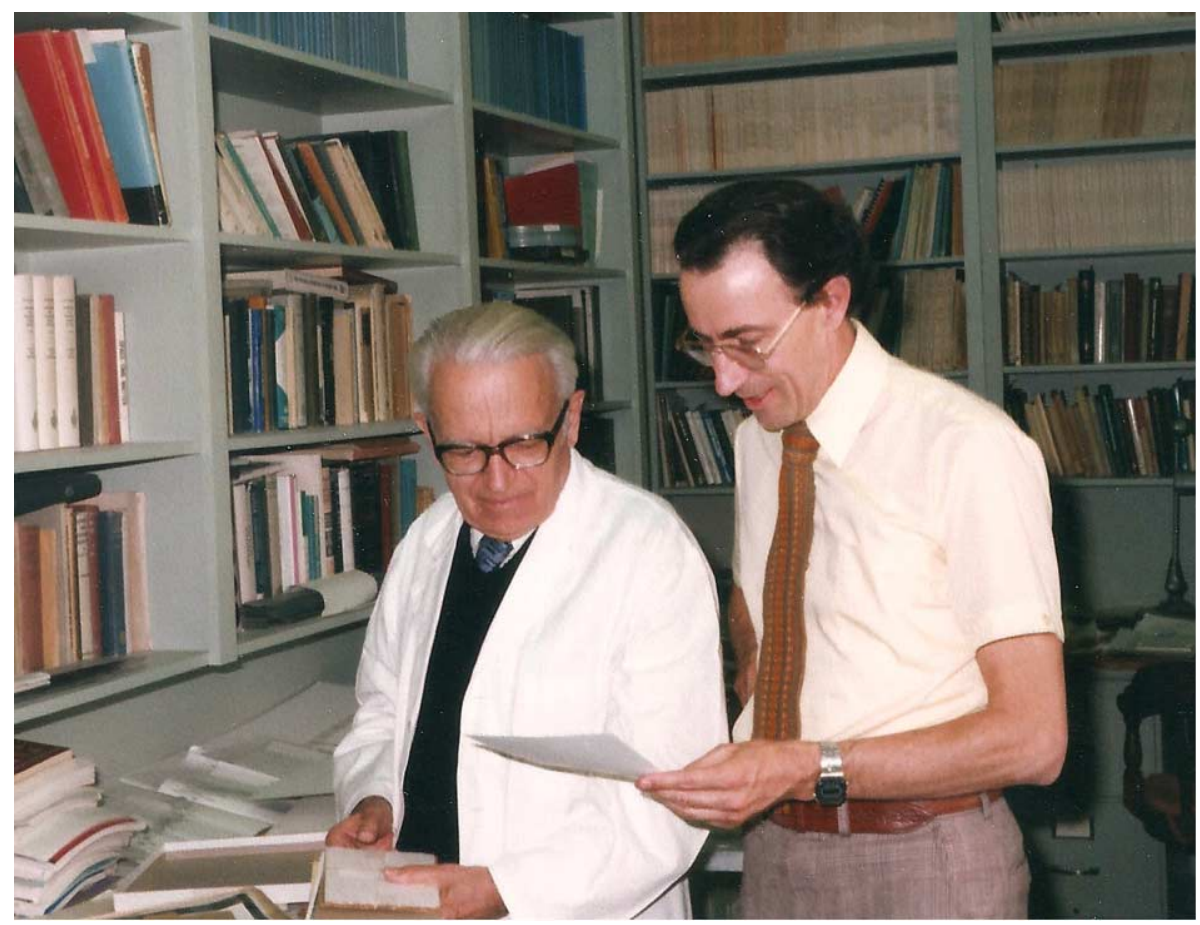

Fig. 2. Photograph of Henry Mantsch (on the right) with the Nobel Laureate Gerhard Herzberg at the NRC in Ottawa (photograph kindly provided by Henry Mantsch).

research environment at the NRC was excellent and Henry was lucky to have world leading scientists as colleagues. This included people like Gerhard Herzberg (see Fig. 2) who worked in the Division of Physics. Henry replaced Norman Jones as the head of NRC's Molecular Spectroscopy Section in the Division of Chemistry in Ottawa in 1978. It was at this point that Henry turned his attention on the application of vibrational spectroscopy in biosciences. This was quite a radical move at that time since the rapidly developing field of Magnetic Resonance spectroscopy was the technique of choice for many researchers at the NRC and indeed elsewhere. Henry was one of the first scientists to apply a Fourier transform infrared spectrometer to analyse biomolecules [1]. His early work involved analysis of lipids but Henry quickly moved on to the analysis of proteins using FTIR spectroscopy [5]. Two of his most cited papers focused on raising awareness about the appropriate use of FTIR spectroscopy, especially about the need to take caution in the recording and analysis of protein infrared spectra [2,6]. The biological spectroscopy community have greatly benefited from these articles.

In the 1990s, Henry embarked on a new journey employing spectroscopic techniques for medical applications especially for disease diagnosis. He moved to the newly established NRC Institute for Biodiagnostics in Winnipeg in 1992. Research work conducted in his laboratory was one of the first to demonstrate the potential of infrared spectroscopy for diagnosis of cancer [7]. This study led to much discussion amongst scientists engaged in biological spectroscopy. Some were very critical of the work whilst others found it highly interesting. Henry is a visionary scientist and he was unperturbed by the criticisms at the time and his laboratory continued to publish in this area [4]. He had the foresight to realise that the technique had the potential to succeed and gain acceptance within the scientific community. Pioneering work, conducted in his laboratory, led to a huge growth in studies applying vibrational 
spectroscopy for disease diagnosis. Thanks to perseverance from many researchers, progress is being made in taking FTIR and Raman spectroscopy from the bench to the bedside.

After spending 35 years as an academic scientist, Henry embarked on a new career with the Canadian Diplomatic Service managing the Science and Technology Section at the Canadian Embassy in Berlin in 2002. He spent five years in this position. Subsequently, he served as Senior Science Advisor to the Department of Foreign Affairs in Ottawa. From being a successful scientist to a diplomat, Henry demonstrated that he is a true interdisciplinary professional. His research studies have been conducted at the interface of chemistry, biology, physics and medicine. He has published over 500 original publications, patents and books. Students from many parts of the world have been trained under his supervision. Some of his former students and post-doctoral fellows are established scientists in both academia and industry. His books have made valuable contribution in the training of graduate students engaged in the use of spectroscopic methods for biological analysis.

I came to know Henry in 1987 when I attended the Second European Conference on the Spectroscopy of Biological Molecules (ECSBM) in Freiburg (Germany). At that time I was a PhD student at the University of London with Dennis Chapman (see Fig. 3). There was friendly competition between Dennis and Henry since both of them used infrared spectroscopy for biological studies. They co-operated with each other and produced joint publications.

Henry is a dedicated and enthusiastic scientist who is well-liked in the scientific community. He continues to be invited to speak at conferences around the world. Over the years, I have maintained contact

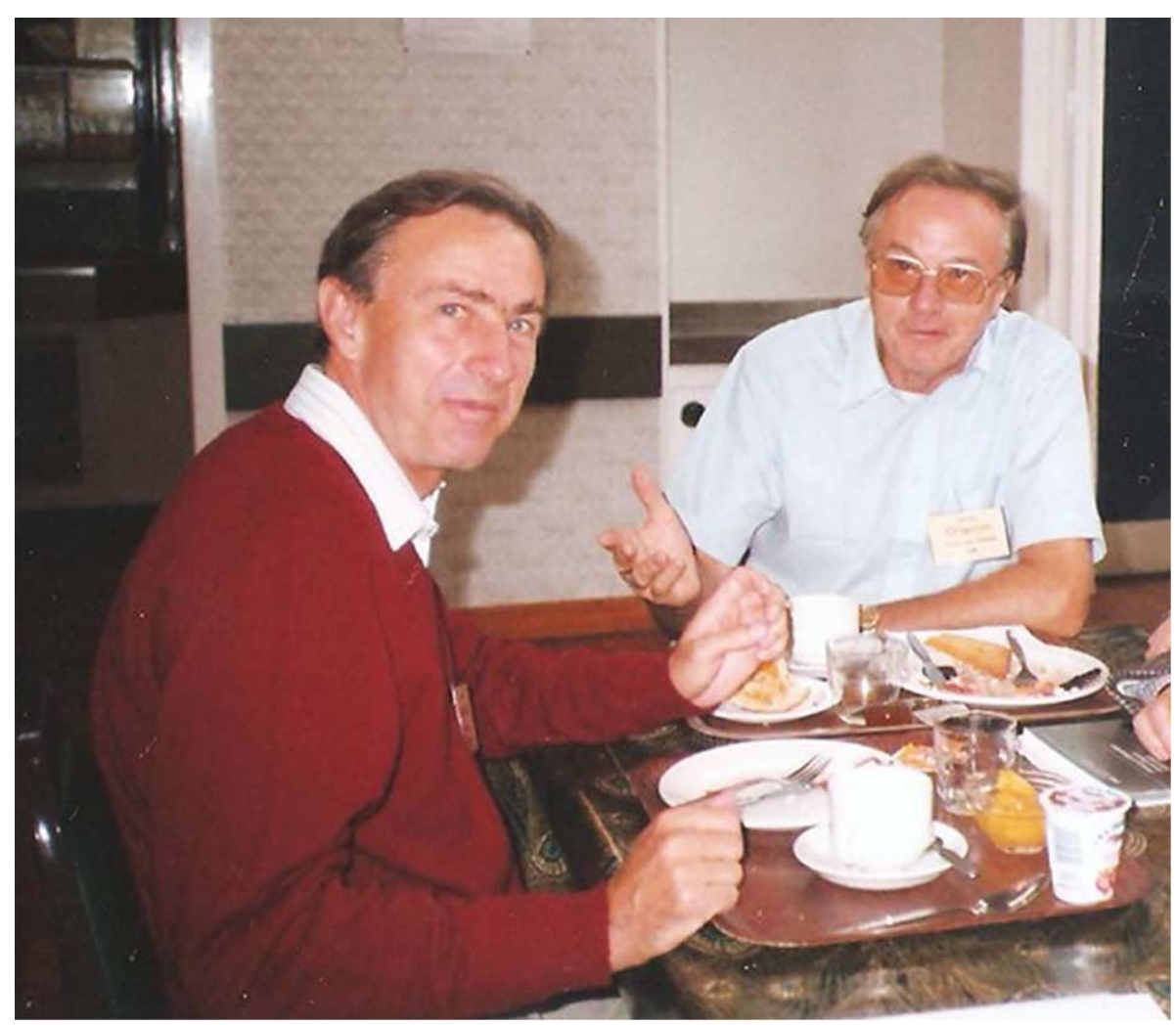

Fig. 3. Henry Mantsch (on the left) with Dennis Chapman at the 1987 ECSBM Conference in Freiburg, Germany (photograph kindly provided by Henry Mantsch). 
with Henry. When I requested him to produce an article, providing his personal perspectives on the development of biological infrared spectroscopy, he readily agreed. This article [3] is included in this issue of Biomedical Spectroscopy and Imaging which also contains some articles from authors who have benefited from research contributions made by Henry.

Henry is truly a visionary scientist whose contributions over the years have helped advance vibrational spectroscopy, especially infrared spectroscopy, from basic science to clinical applications. I very much hope that he continues to enrich and enlighten the scientific community with his vast knowledge and experience.

\section{References}

[1] D.G. Cameron and H.H. Mantsch, The phase transition of 1,2-dipalmitoyl-sn-phosphatidylcholine as seen by Fourier transform infrared difference spectroscopy, Biochem. Biophys. Res. Commun. 83 (1978), 886-892.

[2] M. Jackson and H.H. Mantsch, The use and misuse of FT-IR spectroscopy in the determination of protein structure, Crit. Rev. Biochem. Mol. Biol. 30 (1995), 95-120.

[3] H.H. Mantsch, The evolution of biomedical vibrational spectroscopy: A personal perspective, Biomedical Spectroscopy and Imaging 4 (2015), 315-329.

[4] C.P. Schultz, K.Z. Liu, P.D. Kerr and H.H. Mantsch, In-situ infrared histopathology of keratinization in human oral/oropharyngeal squamous cell carcinoma, Oncology Research 10 (1998), 277-286.

[5] W.K. Surewics and H.H. Mantsch, New insight into protein secondary structure from resolution-enhanced infrared spectra, Biochim. Biophys. Acta 952 (1988), 115-130.

[6] W.K. Surewics, H.H. Mantsch and D. Chapman, Determination of protein secondary structure by FT-IR spectroscopy, Biochemistry 32 (1993), 389-394.

[7] P.T.T. Wong, R.K. Wong, T.A. Caputo, T.A. Godwin and B. Rigas, Infrared spectroscopy of exfoliated human cervical cells: Evidence of extensive structural changes during carcinogenesis, Proc. Nat. Acad. Sci. 88 (1991), 10988-10992. 